\title{
CETERIS PARIBUS PROVISOS, KNOWLEDGE OF REFERENCE-FIXING CONVENTIONS, AND PROPER NAMES. REPLY TO ORLANDO ${ }^{1}$
}

\author{
MARIO GÓMEZ-TORRENTE \\ https:/ / orcid.org/0000-0002-5957-6544 \\ Instituto de Investigaciones Filosóficas \\ Universidad Nacional Autónoma de México (UNAM) \\ Mexico City \\ Mexico \\ mariogt@unam.mx
}

\begin{abstract}
Article info
CDD: 410

Keywords

Ceteris Paribus Provisos

Reference Fixing

Descriptivism

Proper Names

Semantic Knowledge
\end{abstract}

Received: 01.10.2020; Accepted: 17.10.2020

https://doi.org/10.1590/0100-6045.2020.V43N4.MO

\begin{abstract}
:
Eleonora Orlando argues that one must understand some descriptivist theories of names that I criticize in my book Roads to Reference as ceteris paribus generalizations, and that on this understanding they survive my criticisms; she also introduces some doubts about my views on the knowledge speakers have of the reference-fixing conventions I postulate for proper names. In this note I argue against Orlando's suggestion about ceteris paribus provisos and explain my view of the epistemology of reference-fixing conventions.
\end{abstract}

${ }^{1}$ Support from the research project no. PIDPID-107667GB-I00 of the Spanish Ministry of Science and Innovation is gratefully acknowledged.

Manuscrito - Rev. Int. Fil. Campinas, v. 43, n. 4, pp. 35-48, Oct.-Dec. 2020. 
In Roads to Reference (Gómez-Torrente (2019)) I propose that the conventions governing reference fixing for, at least, uses of demonstratives, proper names, and natural kind nouns, can be taken to adopt the form of statements of roughly sufficient conditions for reference (and reference transmission) and for reference failure. I also suggest that attempts to provide accounts of reference fixing for those expressions in terms of a condition which is both necessary and sufficient for reference are unlikely to succeed or, in the case of a few proposals I consider in detail, actually demonstrably unsuccessful. One of the reasons for the failure of theories of necessary and sufficient conditions is that they are unlikely or demonstrably unable to give correct verdicts in cases of apparent indeterminacy as to whether there is reference or not, of which I provide a number of examples-but the counterexamples to the theories of necessary and sufficient conditions don't always involve indeterminacy. The problems posed by most cases of indeterminacy are avoided by the proposal that the relevant reference-fixing conventions give just sufficient conditions for reference and reference failure of the expressions under consideration: the roughly sufficient conditions that it is natural to postulate simply don't have implications concerning most examples of apparent indeterminacy.

This probably doesn't take care of all kinds of referential indeterminacy, however. It may well be that the facts about linguistic behavior that eventually give rise to the constitution of the appropriate conventions cannot give rise to precise general statements that have no exceptions, and it may be that, while we may get close to general statements of the operating conventions, the closest we may get will be as statements of conditions which are typically but not 
universally sufficient. The aim of the reference theorist may well be-in fact, I think it probably is-the relatively modest one of giving as close an approximation as possible to what it is that determines reference (and reference failure), but this may resist formulation in terms of exceptionless general statements, and the closest formulation may be in terms of statements of ceteris paribus sufficient conditions.

That's why I say that the conditions for reference and reference failure that appear to constitute the natural reference-fixing conventions are roughly sufficient. By this I mean, in part, that they are probably to be conceived of as sufficient ceteris paribus, not as sufficient without absolutely any exception. More specifically, there may be some cases where reference does not clearly or determinately take place even though some conditions that appear intuitively sufficient for reference obtain. One particular reason for this that I have in mind in Roads to Reference is that general statements of sufficient conditions for reference that appear fully natural at first sight connect the mental life of a speaker, and specifically her referential intentions (and the existence of some relations between these intentions and aspects of the world at large) with the obtaining of reference (or reference failure) for the relevant expressions as she uses them. While it seems intuitively clear that the conditions I propose as sufficient are in fact such when the mental life of the speaker is otherwise normal, it is probably not completely clear that when the speaker's mental life is sufficiently abnormal the conditions would still be viewed as sufficient. For example, it seems intuitively clear that if I intend to call my child "John", I do not have any conflicting referential intentions, and my linguistic community is not opposed to that, then my uses of "John" will thereafter refer to my child; but this may not be so clear if I develop some form of dementia that (without 
changing my referential intentions) makes me think that "John" is a magical expression that summons the Devil when it is uttered.

Eleonora Orlando (2020) thinks that if the theories of necessary and sufficient conditions for reference that I criticize are interpreted as qualified by a ceteris paribus proviso like the one I add to my postulated conventions, these theories escape all the counterexamples I use against them, including examples based on apparent referential indeterminacy. Her idea is that the proponents of the theories can claim that they are designed to account exclusively for what happens with reference in normal situations, and that the counterexamples I provide can in all cases be claimed to arise in situations which are in some sense abnormal. Even leaving aside the obvious reproach that the proponents of the theories I criticize do not (at any point I can see) qualify their theories by means of ceteris paribus provisos, there are several problems with Orlando's suggestion.

A basic general problem is that it's hard to make sense of the idea of ceteris paribus conditions which are both sufficient and necessary for reference. Can a theorist propose that the condition she is offering as necessary for reference is only so ceteris paribus? This would mean that she is admitting that there are (abnormal) cases of reference that do not meet the condition she is proposing as necessary for reference. But this just doesn't sound right. If the theorist knows that there are cases where reference obtains that are not accounted for by her theory, the theory is evidently incomplete as a theory of reference and she must simply abandon it and look for another theory that accounts for those cases. (On the other hand, the proposal of sufficient conditions for reference which are so only ceteris paribus doesn't place the theorist in a similarly unstable position; the theorist is here simply proposing that there are 
cases where there is no clear reference despite the roughly sufficient conditions obtaining, but then no explanation of a fact of reference is needed, as there isn't any.) Orlando suggests that the counterexamples I give to the necessity of the conditions for name reference offered by Devitt (2015) and Dickie (2011) (see, respectively, Gómez-Torrente (2019), p. 84 (the "Aristotle" example) and pp. 88-89 (the "Khufu" example)) can be avoided if one understands this necessity as merely ceteris paribus (and one counts the situations where the examples arise as exceptional or abnormal). But if these authors accept the counterexamples, what they will do will certainly not be to seek to avoid them by imposing ceteris paribus provisos, but to attempt to account for the cases of reference brought to light by the examples by modifying their theories or proposing new ones.

The related additional complaint must be made against Orlando that the counterexamples in question do not seem in any sense I can think of to be abnormal, at least provided we don't count the very moderate complexity involved in their description as grounds for abnormality. I invite the reader to form an opinion on this matter by reading the description of the examples in question at the cited loci, and specifically to form an opinion as to whether the examples are any more abnormal than countexamples typically found in the literature on theories of reference for names, beginning with standard Kripkean counterexamples to the necessity for reference of classical descriptivist conditions-like the "Gödel-Schmidt" or "Jonah" counterexamples. Surely we would not want to defend descriptivist theories by claiming that the slightly complicated situations involved in the "Gödel-Schmidt" or "Jonah" cases (where there is intuitive name reference to a certain individual who nevertheless does not satisfy the description associated by a speaker with the name) turns 
them into exceptions meant to be excluded by a ceteris paribus proviso added to descriptivism. I fail to see how the situation could be different for my mentioned "Aristotle" and "Khufu" cases. Thus, for example, the "Aristotle" counterexample to Devitt's theory simply exploits the possibility that some early uses of "Aristotle" by Aristotle's contemporaries that are causally related to current uses may have been uses where someone applied mistakenly the name to someone who was not Aristotle. Orlando says: "when someone sees Plato at a distance and then produces a token of 'Aristotle', I would say it is an abnormal use, grounded in Plato by an understandably mistaken perceptual belief'. But if we are to take current uses of a name which are causally related to some earlier mistaken uses as "abnormal", I just don't see what can prevent a classical descriptivist from claiming that cases of association of mistaken descriptive information with a name are "abnormal" as well. I think it's clear that nobody (not even the classical descriptivist) wants that.

This brings us to another complaint against Orlando's suggestion even as concerning the sufficient conditions for reference proposed by the theories she wants to defend. As just noted, her proposal is ad hoc and leads to explanatory gaps when the necessary conditions of those theories are concerned; but in my view it can be seen to be ad hoc and non-explanatory even when we turn to the sufficient conditions. Here the problem is not that facts of reference would be left unexplained if we adopted Orlando's proposal, but that several indeterminacies would be left unexplained. As recalled above, my idea in Roads to Reference is that most cases of referential indeterminacy arise in situations not covered by the conditions given as sufficient by the extant conventions. This provides an explanation of indeterminacy insofar as it enables one to pinpoint the aspects of the situations of indeterminacy that are not 
covered by the existing conventions - the "abnormal" situations, if you want to call them that. The problem with Orlando's proposal now is that merely adding a ceteris paribus proviso to (the sufficiency part of) a theory such as Devitt's or Dickie's doesn't explain indeterminacies, as it doesn't pinpoint any such aspects, and if left at that, is a purely ad hoc move. Orlando does evidently feel the need to flesh out the idea of abnormality that the move presupposes, and to flesh it out in such a way that the move does not appear ad hoc. But since the move is not based on what I take to be the proper understanding of the sources of indeterminacy, but merely on a desire to save some preexisting accounts that don't give indeterminacy its true role (or any role), Orlando's attempts to flesh out the idea of abnormality are foreseeably problematic.

To begin with, consider the counterexample I offer to the sufficiency for reference of Devitt's and Dickie's theories, namely the "George Smith" example from Kripke ((1972), 95-6). ${ }^{2}$ This is a case of apparent referential

${ }^{2}$ This is how Kripke introduces the example there:

If . . the teacher uses the name 'George Smith'-a man by that name is actually his next door neighbor-and says that George Smith first squared the circle, does it follow from this that the students have a false belief about the teacher's neighbor? The teacher doesn't tell them that Smith is his neighbor, nor does he believe Smith first squared the circle. He isn't particularly trying to get any belief about the neighbor into the students' heads. He tries to inculcate the belief that there was a man who squared the circle, but not a belief about any particular man-he just pulls out the first name that occurs to him-as it happens, he uses his neighbor's name. It doesn't seem clear in 
indeterminacy, as it's intuitively unclear whether the students of the example can make uses of "George Smith" that refer to George Smith, and yet the theories of Devitt and Dickie imply that they can. Orlando says:

the example of George Smith can be clearly classified as an abnormal case, since the teacher does not have the intention to use the name to refer to his neighbour, as it would happen to any normal case of insertion, by reference borrowing, in a communication chain leading to the neighbour; it is comparable to the use of a random or invented name.

But clearly this cannot constitute grounds for calling the case "abnormal" and in this way explain the impression of indeterminacy. First, Kripke doesn't say that the teacher does not intend to refer to his neighbor with "George Smith", but merely that he uses the first name that comes to his mind for his mischievous purposes. (Note that, since Kripke does explicitly include as a condition on successful reference transmission that the receiver intend to refer to the same thing as the transmitter, if he had thought of the example as one where the teacher does not have any referential intention, then he would have simply noted that that condition excludes the case as one of successful reference transmission; but he doesn't.) But second, suppose that we just build into the example the explicit stipulation that the teacher does intend to refer to his neighbor; then the impression of indeterminacy does not

that case that the students have a false belief about the neighbor, even though there is a causal chain going back to the neighbor. 
disappear, so it can evidently not have been originally due to a fact about the intentions of the teacher. The proposal in Roads to Reference traces the indeterminacy in the "George Smith" case to the fact that the case doesn't satisfy a condition which appears among some natural sufficiency conditions for successful transmission-namely that the receiver doesn't form at the transmission stage a set of beliefs involving the received name that on the whole conflict with the beliefs of the community of users of the name at large. This provides an explanation of the feeling of indeterminacy that is not ad hoc, as it derives directly from the proposed account of reference fixing - and an explanation of the "abnormality" of the case, if you will.

Orlando's proposal, if it is to be explanatory, requires also an account of abnormality for several other cases of indeterminacy that do not present extensional problems for Devitt's or Dickie's theories. Among these are cases of conflicting referential intentions (see Gómez-Torrente (2019), 74-5). But Orlando's suggestions are again inadequate. Consider the case of Marco Polo's uses of "Madagascar" in the story often attributed to Gareth Evans. In this story, Marco Polo inherits the name "Madagascar" from some Arab sailors while he is seeing the island now known as "Madagascar", but the sailors don't use the name for the island but for a part of the African continent, and Marco Polo is confused. Now he has both the intention of referring to what the sailors referred to and the intention of referring to the island, and these are in conflict. In my view, the uses of "Madagascar" by the confused Marco Polo don't clearly have a reference, and Orlando agrees. But in attempting to justify her thesis that the case must then be abnormal, she says that "the situation is not the normal one because the name [(“Madagascar")] has not still acquired its referent". Again this clearly cannot be a reason why the case is abnormal- 
how could something that has not even occurred at that point (that "Madagascar" acquires its (current!) referent) be the reason why a use of a name is abnormal? The proposal in Roads to Reference traces the indeterminacy in this case again to the fact that Marco Polo forms beliefs at the transmission stage that on the whole conflict with the beliefs of the existing community of users of "Madagascar" at large. (He forms the belief that Madagascar is the island that he is seeing, for example.) So here again the case doesn't satisfy a condition which appears among the natural sufficiency conditions for successful transmission, and thus we get a non-ad hoc account of the indeterminacy/"abnormality" of the case.

Or consider what Orlando says of my "Tim" example: ${ }^{3}$

in the Tim example, the speaker is in the grip of another kind of mistake, which causes his introduction of 'Tim' to be grounded in two different trees, unbeknownst to him. Did he fail to refer or did he succeed in referring to

${ }^{3}$ This is how I present it in Roads to Reference:

suppose I am in a thick forest, with my visual attention focused on a tree top and with my hand touching what I tacitly but wrongly assume to be the same tree's trunk. I say I'll call this tree "Tim," with the intention of referring both to the tree I'm seeing as represented by my visual perception of it and to the tree I'm touching as represented by my tactile perception of it. What is the reference of "Tim," if any? Is it the tree I'm touching, or the tree my visual attention is focused on? Or is it conventionally determined that there is reference to neither? Again I think there is no clear answer. (Gómez-Torrente (2019), 75) 
some object? The answer may depend on our ontological commitment; for instance, one may think that he succeeded in referring to a tree-fusion constituted by the combination of his two perceptual states.

The indeterminacy/abnormality seems again to be said to be explained by the existence of a mistake, presumably the mistake of forming two conflicting referential intentions. But this cannot be the basis of indeterminacy/abnormality, for, as Roads to Reference and many items in the literature make abundantly clear, cases of conflicting referential intentions are by no means unusual, and they often do not lead to indeterminacy (for example, they do not lead to indeterminacy when there is a single perceptually based referential intention that overrides the others; see GómezTorrente (2019), 54ff., 93-4, n. 16). (Orlando's suggestion that the speaker may have succeeded in referring to a "treefusion", on the other hand, is puzzling, and not just because, in considering the case abnormal, she appeared to grant that it was one of indeterminacy: how could the speaker have referred to something he didn't intend to refer to?)

In sum, what is wrong with the idea that one can save Devitt's or Dickie's theories by merely adding (to their sufficiency part) a ceteris paribus proviso is that this is ad hoc because it doesn't give us a natural explanation of the sources of abnormality/indeterminacy. When one attempts to provide an independent explanation, one which, unlike the one offered in Roads to Reference, will inevitably be theoretically disjointed from the provisoed theories, what we'll get will more often than not be inadequate.

Orlando asks for a number of clarifications concerning my view of the knowledge that speakers have of the reference-fixing conventions whose existence I postulate. 
She asks, specifically, whether I think it's propositional or practical knowledge, and whether I think it's semantic or not. As noted above, I doubt that the conventions as I state them are fully and precisely constituted by extant linguistic behaviors, and probably they are at best a theoretical approximation. A fortiori, speakers cannot be said to know the corresponding propositions; they have, however, a familiarity with them that we can perhaps picture as a kind of practical knowledge, a familiarity that allows them to observe the conventions via simple behaviors, such as instances of acceptance or denial that certain specific things are being talked about with particular uses of proper names. (Strictly speaking, of course, it is these behaviors that help constitute the conventions as such.) Nor is the speakers' knowledge a knowledge of specific conventions about specific names; against the hopes of the descriptivist, there is no reason to think that a speaker knows or can after sufficient coaching know the proposition that the name is coreferential with a particular hyper-complicated referencefixing description. All a competent speaker needs to know as regards name reference fixing is how to recognize as appropriate the particular cases of the reference-fixing conventions instituted by her linguistic community. This is a strongly anti-descriptivist picture, but to the extent that it attributes to speakers a type of knowledge of referencefixing conventions, and given that some (super-strongly) anti-descriptivist authors do not require or do not clearly require such knowledge of competent speakers, it may at first sight appear as "descriptivist" (in a spurious sense).

Is this knowledge of the conventions "semantic", or not? Of course the important thing is not so much how we call it, but to be clear about what we choose the term "semantic" to mean, and then to determine whether the knowledge in question qualifies as "semantic" under our definition. Apparently Orlando likes to reserve "semantic" 
for knowledge of truth conditions (of sentences containing proper names, in the case that concerns us), or for knowledge that directly generates knowledge of truth conditions. On this meaning of "semantic", the knowledge of reference-fixing conventions that I think speakers have is not semantic, as knowledge of the conventions (even propositional knowledge of the conventions, if this existed) would not automatically provide a speaker with knowledge of the truth-conditional contribution of a name to the sentences in which it appears. (This is again an antidescriptivist aspect of my view.) But there is no substantive reason (aside, perhaps, from a certain consolidation of the use that Orlando has in mind) why we should strictly reserve "semantic" for "truth-conditional". Other aspects of linguistic competence can be called semantic without any stretch, and in fact are routinely called "semantic" in the literature. An example is provided precisely by the conventions postulated as giving the reference of demonstratives. Kaplan does not hesitate to classify the rules he calls characters as part of the meaning of demonstratives, and hence as "semantic" provided we count "meaning" in Kaplan's sense as part of semanticsbut Kaplan's characters are not part of the truthconditional contribution of the corresponding demonstratives. I would say the same in the case of the reference-fixing conventions I propose for demonstratives in my book. And in my view, such conventions are not substantively different from the reference-fixing conventions for names-in particular, competent speakers must have suitable knowledge of them. Hence, I have no misgivings about calling this knowledge "semantic", even if by itself it doesn't provide a speaker with knowledge of the truth-conditional contribution of a name.

Orlando's final question is whether there is any view of fictional names that fits especially well the account of 
reference fixing in Roads to Reference. The topic of fictional names is complex and I would try not to say much about it even if I had the space to do it (which I don't). Let me just say that the account in the book is certainly compatible with all the broadly anti-descriptivist theories of the topic that I am aware of. For example, it is compatible with a Kripkean theory on which names in a work of fiction are used under a certain sort of pretense that they refer in the usual way, and hence, presumably, that they have obtained their referents in the fiction via pretended conventions like the ones I postulate for the real life case. And it is compatible with a Kripkean view that outside fiction, names may at least sometimes refer to corresponding fictional characters; fictional names, as Orlando notes and I also note in Roads to Reference (see Gómez-Torrente (2019), 99 , n. 21), might get referents or get transmitted via some of the conventions I postulate in the book.

\section{REFERENCES}

Devitt, M. (2015), "Should Proper Names Still Seem So Problematic?", in A. Bianchi (ed.), On Reference, Oxford University Press, Oxford, 109-43.

Dickie, I. (2011), "How Proper Names Refer", Proceedings of the Aristotelian Society 111, 43-78.

Gómez-Torrente, M. (2019), Roads to Reference. An Essay on Reference Fixing in Natural Language, Oxford University Press, Oxford.

Orlando, E. (2020), "Walking the Roads to Reference. Some Comments on Mario Gómez-Torrente", Manuscrito, this issue.

$(c c)$ BY 